\title{
Irrelevance of Basic School Education in Nepal: An Anti-Colonial Critique on Problems and Prospects
}

\author{
Shree Krishna Wagle \\ Bal Chandra Luitel \\ Erling Krogh
}

\begin{abstract}
Despite its contextual, theoretical, and practical relevance, contextualized teaching and learning has not been the priority of school education of Nepal. The policy provision of local curriculum and the use of locally available resources for teaching and learning have continuously lost its position in educational circle. To this background, taking anti-colonial critical stance, this paper analyses problems and prospects of contextualized teaching and learning in school education of Nepal. Taking evidences from the first author's lived experiences, and experiences from a Participatory Action Research (PAR) project in a public school of Nepal, the paper exposes manifold challenges and dilemmas initiated by Westernmodern educational ideologies, and promptly illustrates how those uncritically imposed/accepted schooling agendas were responsible to demolish rural (and indigenous) identities of Nepal. The paper eventually proposes policy makers and curriculum practitioners of Nepal to pursue agency in school education, making it more place-relevant; enabling school graduates to learn to 'live' (rather than 'leave') their place.
\end{abstract}

Keywords: school education, anti-colonial lens, rural/indigenous identities

\section{Setting the Scene}

Originally, I, the first author of this paper, am from Gorkha. It is a rural located district of western Nepal. I grew up in a small village, Simal Taar. Situated in the hillbasement, the village covers slop-sides of a flowing stream, Jyadul Khola. Climbing up the eastern hill is a village called, Borlang, and climbing up the western hill is another village called, Mailung. The land is fertile and irrigation is easy. I spent the first decade of my childhood days there, down the hill in Simal Tar, and up the hill in Mailung. In Simal Taar, which was also called Lamichhane gaun, there were around twelve houses. Likewise, Mailung, which was also called Wagle gaun, was a community of around fifteen families living together. Agriculture and livestock farming was the major income source of the villagers.

I left the village when my family migrated to Chitwan (a district in southern Tarai) in mid 1990s. During those days mass migration of seemingly well-to-do families from Gorkha to Chitwan was commonly observed. Most of the migrants were attracted by the plain landscape, and easy life-world of Southern Tarai. Maoist insurgency ${ }^{1}$ was another possible reason behind it. In the case of my

1 Nepal communist party Maoist began armed revolution (people's war) since 1996 family, my father's intention to send me, my brother and two sisters in English medium school was the major reason for our migration.

After 20 years that our family had migrated to Southern Tarai, I got an opportunity to visit my village, Mailung and Simal Taar, where I had spent my childhood days. The house which my family had left some 20 years earlier, though completely ruined, was still there in the village. Following the similar destiny of my house, there were few other ruined houses here and there around the village. I came to know that most of my relatives and neighborhoods from both Simal Taar and Mailung had already migrated to urban locations. Most of the lands in the village were bare. There were no youth to work in the field. In few families of my relatives, who were still there, there were rarely the male members. Possibly, they had gone to Kathmandu, or overseas for work.

The next morning, Thula ba (my father's elder brother) served me a cup of milk tea. Milk tea was always my favorite.

"How many buffalos do we have Thulo ba?" I asked.

He laughed and said, "Buffalo! No Chora (son)! Buffalos are only in our memories. Drinking fresh milk has already been past stories in the village"

It surprised me. I remembered my childhood days where there would be no house in the village without buffalos. 
"Then, how you prepared this milk tea, Thulo ba?" I inquired.

He smiled and said,

"It's from the milk powder I bought from the shop".

Milk powder in the village! His remarks surprised me.

"There is no one to look after buffalos". He pointed to the meadow outside and said, "See, there is no one to cut the grass for animals. Younger people don't stay in village".

"In the whole village, there are only two or three families who have won buffalo".

I observed similar life-world in yet another village as well. It was August 6, 2017. As a part of my PhD studies, along with other fellow researchers and a senior professor of education (the second author of this paper), we made a short educational visit to rural Kavre (A hilly district in central Nepal). We were there to select five public schools for our action research project in education. Climbing up the Bhakundebaesi, we moved to Dapcha communities. The village reminded me the village in Gorkha, which my family had left long before. There were many ruined houses locked from outside. Large area of land around the roadside was bare.

One of our fellow traveler, who also happened to be the local leader of the village said, "Our village is going empty. Once it was the most populated village of Kavre. You know, it was a renowned trade centre".

He pointed to a small Hindu temple to the right and said, "This place was also the centre for art and culture."

While he was saying this, we could see old temples and monuments with fine architectural design on the road sides.

He pointed two old-looking houses with locked door and said, "Possibly, the families have shifted to Kathmandu to educate their children in an English medium school".

He added, "It has been a popular culture in our village that when husbands go to foreign countries for job, wives generally shift to rented house in Kathmandu in the name of educating their children" (Field note, August 6, 2017).

Thereafter, we (the first author, the second author, and the fellow researcher) raised several issues that questioned the idea of sustainable development, rural justice, and ongoing schooling practices of rural Nepal. Would those male members go to foreign land for job in case they were educated in a way to use their own locally available resources for income generation? Would those housewives go to live in the rented house of Kathmandu in case they were convinced with the quality of education for their kids in their own village? Most importantly, do those children who are fantasized with the glory of city life since their childhood days will readily return to their village after they complete their education in the city?

There, we reflected on our own role as university researchers and educators as well. How could we contextualize our public school teaching and learning, and enable our high school graduates to make their every-day living from wise and sustainable use of locally available resources? How are the current initiatives of Nepal government (if any) to contextualize school education of rural locations?

\section{Approaching the Inquiry Agenda}

Starting from 2017, in my role as PhD research-degree student, I began to work with NORAD ${ }^{2}$ Rupantaran project at Kathmandu University School of Education (KUSOED). The project initiated participatory and rights-based approaches to improve teaching and learning outcomes of basic school students through community empowerment, and sustainable improvements. Initially five (later it increased to eight) of the $\mathrm{PhD}$ research degree students from Tribhuwan University (TU), and Kathmandu University (KU), Nepal, facilitated action research project in 10 different schools from three different districts of the country (Kavre, Chitwan, and Nawalparasi). Under Rupantaran umbrella project, we, the university researchers from both universities initiated individual sub-projects within interconnected themes i.e., education, health outcomes, and livelihood prospects. Growing in transformative educational research culture at KUSOED (see Luitel, 2009; Wagle, 2016), my individual research interest from very beginning was more concerned around exploring manifold pedagogical possibilities for individual and social transformation.

From Kathmandu University, our research team selected five schools located in Dapcha community of Kavre district. About 50 kilometers North-East from capital city, Kathmandu, Dapcha is a rural location with hilly landscape. The landscape is characterized by terrace cultivation, and steep hillsides. Among five selected schools in Dapcha community, we selected Shree Janaheet School as leader (action) school for Rupantaran action research project. First, we were to work in leader school; and thereafter, take the experiences and learned lessons to other four initially selected reference schools.

For the first eight months, through Participatory Learning and Action (PLA) activities, our research team (university researchers and research supervisors) explored the communities and its cultural landscape. We were engaged in activities, which could possibly strengthen our 'place-sense' (McKenzie \& Tuck, 2015). Doing so, our intention was to set the study grounding, and strengthen our intimacy through insider-outsider communication in the community. We, the university researchers, regularly visited the community and stayed there for weeks. We made photographs and video recordings of the actual life-world and cultural landscapes of the community. We climbed up and down the hills. While walking around, we shared informal talks with the villagers. We had tea together in local shops and nearby chautaras ${ }^{3}$. It enabled us to develop our familiarity with the community pertaining

2. The Norwegian Agency for Development Cooperation. It grants funding to organizations within civil society, research, higher education and private sector development that work with partners in south Asian and African countries.

3. A place under big Peepal tree, where villagers rest and share their sorrow and happiness to each other 
to its past and present, its culture, natural resources, climate, demographic situation, and people's way of living. For whole eight months I was more concerned with the decreasing trend of population in the village, the bare land around, and uncontrolled mobility of educated/uneducated youth from village to the city.

These eight months of the initial phase followed the planning phase, where our research team discussed the outcomes of phase 1 to reflect on current pedagogical practices of the school under study through the participatory needs assessment. The ideas generated in those sessions became the starting point for the participants to go through participatory action learning cycles. Following it, in July 2018, we (the $\mathrm{PhD}$ degree research students) conducted four days (three hours each) workshop in the leader school.

In group discussions most of the teachers were worried on decreasing trend of students' number in the school.

"Parents find their pride and prestige in sending their children in English medium private schools", a teacher said.

"We have been educated to value passing an examination more than developing knowledge, and practical skills", said another teacher.

Teachers also questioned the relevance of course contents and lessons they teach in the class.

"Most of the course contents I teach in my class are not familiar to our students' actual life in this community", said a Social Studies teacher.

Other teachers repeatedly raised the issues pertaining to weak school community linkage. It showed they were worried about students' limited knowledge about the place where they were growing, and their weak sense of belonging. During interactions, I would ask to myself, "Isn't it that the present predicaments of village are rooted in its decontextualized schooling practices?" I discussed it with both of my research supervisors, the second and the third authors of this paper. It is to this background, taking supports from my research supervisors, I began to explore on the question:

What are the (hidden) factors responsible for decontextualized teaching and learning in school education of Nepal?

The four days' workshop followed other methods of participatory needs assessment like (1) In-depth interview and FGDs among subject teachers, parents and students, and (2) resource mapping and situation analysis of the school, and the community, where the school was located. Evidences from these methods were more helpful in prioritizing needs as previously identified in four days workshop, making it more inclusive of stakeholders' voices.

Starting from July 2017 to July 2019, I, the first author of this paper, made journal entries of events and experiences where I could sense the relationship between immediate place-context and curriculum practices of the schools within that place. The more I began to reflect the experiences (as articulated in my journal entries) in their relations to policy literatures and research studies in the field of school education of Nepal, the more I was exposed to 'pedagogical displacement'. I observed that there were almost no attempts (both at the school and the community level) to link school learning with community realities. The concept of local curriculum and formative assessment was poorly implemented (Subedi, 2015), which were largely devoid of contextual realities.

\section{Inquiry Approach and Theoretical Perspectives}

Under PAR project, this paper makes critical place reflection (McKenzie \& Tuck, 2015). Critical place reflection, as place-based knowledge episteme, is a way of approaching an understanding of place-specific lived experiences. It plays more attention to the 'where' of the research. Decolonizing conceptualization (McKenzie \& Tuck, 2015) informed through critical anti-colonial lens enabled me to examine the hegemonic control of Nepali educational practices by developed (economically and politically powerful) countries through their own interest of education, limiting the capacity of this country to come with its own contextually relevant educational agendas. Since Nepal was never under the direct control of external political power, looking from the surface, my use of anti-colonial critique may not correspond with Nepal's historical reality. However, being mindful on it, in this discussion, I have used anti-colonial as mere philosophical and theoretical perspectives (lens) and approaches to understand power domination of economically and politically powerful nations to less powerful nation, Nepal. It offered me the philosophical insights to challenge western-modern discourses. Further, Ranciere's (2007) orientations to economic order enabled me to reflect on how power as function of knowledge defines the 'reality' of multinational aid agencies (e.g,, World Bank) in flourishing neo-liberal capitalist interest through their own definition of 'modern' education.

\section{Evidence generation and interpretation}

Most of the field experiences in this study are generated from the use of informal talks, which McKenzie and Tuck (2015) calls them the 'subconscious narratives', which formal meetings couldn't bring. Other data collection methods included participatory workshops, reflective meetings and reflective journals. In many cases, the research team captured evidences by means of audio/video recording and note taking. Thereafter, we (the university researchers) transcribed the audio/video recorded evidences and analyzed the evidences following a thematic analysis procedure.

\section{Working within the Milieu of Practice Architectures}

This section, the research findings, brings evidences from initial PAR phases i.e., the phase 1 (exploring the place) and the phase 2 (participatory needs assessment) of the PAR project in the study (action) school and the community. I (the first author of this paper) bring three 
different incidents (and/or dialogues) from my journal entries. These incidents give a glimpse of decontextualized pedagogical practices in public schools of Nepal. The first incident reflects how falling under neo-liberal (global) political agenda of labor market, parents from rural Nepal understand learning as mere securing good exam results. It also reflects their overly romanticized belief on English medium schools. The second incident reflects how in imitating western modern ideals of education, there is long established widening gap between centrally designed educational policies and actual implementation practices in the public schools, particularly the schools from rural locations. Likewise, the third incident reflects the outcome of decontextualized school education, where as school graduates are not prepared to get connected with their own place and available local resources, they are continuously looking ahead to leave their place. All three incidents, in a way or other, illustrate present predicaments of dislocated educational values as ever expanding in (rural) Nepal. In the discussion section that follows, as mentioned earlier, I have discussed the experiences from anti-colonial critical perspectives. Here, I begin with few dialogues from the university researchers' interactions with the participants in Parents' FGD.

Researcher 1: What do you like your child to do at home after school?

Parents 1: I want her to complete her homework.

Parents 2: But teachers in this school don't give enough homework to students.

Researcher 2: Don't you like to see your child doing kitchen works, and helping you in kitchen garden?

Parents 2: I like it. But now is their time to study books.

Researcher 2: Helping parents in kitchen garden is also learning, isn't it?

Parents 1: This doesn't give her marks in the exam. We are there to work in the field. She needs to concentrate on her studies. (PhD Field note, August 15, 2018)

The dialogues in this interaction between the university researchers and the parents suggest that educational focus of Nepali communities has long been detached from preparing 'learners for life'. Instead, it is to prepare 'learners for good exam results'. Almost all participants in Parents' FGD stressed the purpose of school learning as a preparation for either further education or for labor market in city areas. Such an understanding of school education as means for mere memorization of facts for good exam grades was responsible to dislocate school learners from knowing their place, their immediate landscapes and the communities. For example, in an informal 'tea discussion', one of the parents said, "Next year I will take my son to a boarding school, down in Dhulikhel. I don't think he will get good exam marks here in the village-school." There, we read the cultural mindsets of the parents that they have grown up to understand school learning as some cognitive exercises inside the classroom. They are fascinated with privately owned English medium schools. Their success in learning is measured through exam results. Therefore, parents want their children to get detached from household activities, and field works.
We, the university researchers, observed dilemma among school teachers, and administrators on what is 'meaningful' in quality education. The dilemma aroused from the structural and functional challenges and gaps between the policy authorities, the school, and the parental communities. Our first observation was that the school was sandwiched between dislocated policy provisions of central authorities and the expectations of parents for good exam results of their children. The following dialogues, which we experienced in teachers' group meeting reflects the mess of this kind. After participatory needs assessment, the university researchers and the school teachers/ administrators began cycle 1 of the PAR process, sharing prevalent policy-practice gaps in school education. In the first group meeting that followed needs assessment workshop, one of the teachers reviewed The National Curriculum Framework (NCF, 2005) of Nepal and shared in the group.

"It has given focused concern to context-responsive need-based education", he shared. "But the framework is still silent on 'what' and 'how' of contextualized teaching and learning in actual classroom.

"Central bodies prescribe course books. They ask us to finish teaching course contents from the books on time. Exam questions are asked only from the book contents. Community judge our school performance based on the exam results of our students. Under such circumstances, how can we take class room teaching and learning out from the four walls?" interrupted another teacher.

While discussion was still going on, a Social Studies subject teacher brought a book on local curriculum from the school library.

"It is not that the government of Nepal has not taken any initiation for contextualized teaching and learning", he said. "Through local curriculum policy provision, a small step has been initiated as curriculum decentralization practices".

He raised the book little forward (and little upward) and shared, "Curriculum Development Centre (CDC, 2010) has published directives related to the local curriculum. It has given rights to individual schools to design their own curricula".

Despite this initiation of the government, most of the participant-teachers repeatedly stressed that Shree Janaheet School, like many other schools in Nepal, was not able to develop and implement local curriculum. In this line, The Head Teacher said:

Personally, I like the idea of integrating local curriculum in school education. But, only an initiation made by one school is not sufficient enough to develop separate curriculum by the school. Policy level authorities are not serious on this. Without making enough preparations, they prepared guidelines and asked schools to develop curriculum of their own. But, it is not an easy task. Once I had put this issue in front of RP (Resource Person). He took no interest on it. I think, RP himself has no idea on it. I am surprised why government brings new policy without making enough preparation for its implementation. ( $\mathrm{PhD}$ field entry, August 19, 2018) 
As the discussion continued, we got to know that the concept of local curriculum and contextualized learning was poorly implemented in the school. The school was teaching 'additional English' as local curriculum.

"Additional English subject as local curriculum!” it surprised us.

"Yes, in the name of local curriculum, we are teaching additional English. We are not alone to do this. Many other nearby schools are doing the same", said a teacher teaching mathematics.

"We have no option. Parents want us to add more English subjects. If we don't, they will take their children to boarding (English medium) schools", shared another teacher.

"I don't know why central (policy level) authorities are so indifferent to implement their own policy provisions. Same thing has happened with CAS (Continuous assessment of students). There are policy guidelines, but no school has ever followed them", said the head teacher.

The discussion raised many questions pertaining to policy practice gaps in school education of Nepal. Why do central policy authorities bring such policy provisions which they can't actually implement at schools? Why the educational ideals of 'rote learning and securing good exam results' is so deeply rooted in educational circle that no other reform agendas work effective? Why can't schools come with their own reform agendas that suit their uniquely formed socio-economic and cultural contexts? Perhaps, the reason for present crisis of the growing number of displaced school graduates in rural Nepal is somewhere between these questions. Looking through anti-colonial theoretical lens, this article discusses the detail of reasons in the discussion section below.

Before this, here, I bring a few dialogues from an interaction between me and current school graduate from the study school, which illustrates how growing in decontextualized school learning, dislocated values are elevated in the mind and heart of Nepali youngsters. There, as $\mathrm{PhD}$ researcher, I was continuing with participatory needs assessment of the school, and Ranjit (name changed), the school graduate of the same school was assisting me in the assessment process. When I asked him his future career plan, he said:

Ranjit: I spent ten years in this school. Now I will go to Kathmandu.

Me: But your father said you will be continuing your study here.

Ranjit: (Mokingly) Old man! What is here? (Some seconds of awkwardness) I am planning for passport.

Me: Passport? You mean you want to go abroad?

Ranjit: If buda (referring to his father as old man) allows.

Me: Which country?

Ranjit: (silent for sometimes) I don't know. Let's see.

Me: what will you do there?

Ranjit: (Again some seconds of awkwardness) don't know (making his hair raise upward with the support of his right hand) I earn money there. (PhD Field note,

August 14, 2018)

Ranjit was a representative voice of many other high school graduates of the village. That day, based on the discussion between me and Ranjit, I went more thoughtful with few related questions in my mind. What is the actual meaning of learning at school? Why our school graduates, particularly in the rural contexts, are learning to 'leave' their place instead of 'living' it. It reminded me the villages going empty in Gorkha, which I have narrated in the initial paragraphs of this paper. It also reminded me the interaction in parents FGD, where the parents understood school learning as preparing their children to leave their place. What and where is the actual 'root' of this problem?

\section{Encountering the Debate}

Arriving at this stage, I start the discussion from a common debate in the field of curriculum, whether the school curriculum needs to be universal or contextual. Commentaries on globalization forwards a current notion of the world that it is 'flat' ${ }^{4}$ and therefore, 'placeless'. This school of thought eloquently advocates universal ideals in education, particularly the fundamental knowledge base the school education is supposed to carry. Denying time and space barriers, it seeks the universally acclaimed 'standard school curriculum', and encourages school graduates to value 'other ways' of being, and thereby leave their seemingly 'ignorant' and 'uncivilized' communities in order to 'succeed' (Corbett, 2007). Parallel to this, there is opposing school of thought, which holds that globalization is the new word for imperialism. For this group of people, things get authentic meaning only in relation to where it belongs. In other words, if school education is not connected to the place where it is practiced, it cannot assure the relevance of teaching and learning (Taylor, 2007); and therefore, it cannot truly foster the sense of belongingness among school learners

Seen from the lens of these two schools of opposing thoughts, Nepal seems to have fallen in the politicaleconomic grip of neo-imperialism. It has already passed through 'long-accepted' decontextualized pedagogical practices. Under Panchyat 5 nationalism, The National Education System Plan, 1971 introduced uniformed curricula all over the country. Seeing education in human capital and economic terms, it legitimized western-modern ideals of 'universal standard' in school curriculum (Awasthi, 2004). However, with political turn (re-establishment of multi-party democracy, 1990) major changes in education policy, particularly in educating school learners based on their local (place-based) needs began to be seen in the school curricula of Nepal. It was more visible in the policy documents like the National Education Commission (NEC), 1992 and High Level Education Commission (HLNEC), 1998. Later, national Curriculum Framework (CDC, 2005), with its policy provision for local need based learning, gave 'serious' concern to contextualized teaching and learning. Going a step ahead, Nepali

4. The World is Flat is the title of 2005 international bestseller by Thomas Friedman that describes how globalization and technology have reshaped the global labor market.

5. Direct monarchial nationalist rule in Nepal, starting from 1960 to 1990 . 
education policy even made a provision for separate local curriculum, where Curriculum Development Centre (CDC) published directives related to the local curriculum (CDC, 2010). Nevertheless, in spite of seeking context specific pedagogical practices as envisioned in education policy documents, no improvement of any kind is observed in practice level (Subedi, 2015). Despite various policy reforms, the classroom culture in Nepal remained the same (Luitel \& Taylor, 2005). Falling under the influence of geo-economic 'necessity' of neoliberals, schools in Nepal rather uncritically adopted, and thereby continued universal perspectives on education (and school curriculum) in relation to international standards. This, according to Luitel (2009), established pedagogical image in Nepali communities as 'teaching and learning for test'.

\section{Borrowed Agenda and Displacement}

Perhaps, it is the reason that although Nepal experienced massive growth in students' school enrollment soon after the re-establishment of multi-party democracy in 1990, such exponential growth has been accompanied by manifold challenges and dilemmas. Perhaps the root of the problems pertaining to (in)effective implementation of contextualized curriculum is somewhere around it, which I have discussed below under two sub-headings i.e., 'neocolonial predicaments', and 'dislocated values'. They suggest how western-modern agenda of education (as major underlying cause of decontextualized curriculum), when uncritically adopted by Nepali educational policy makers, most of the educational creed those borrowed agenda advocated eventually became irrelevant to actual context of this nations' uniquely shaped life-world (Luitel $\&$ Taylor, 2005). Here, I forward some justifications for my arguments.

\section{Neocolonial predicaments}

Basic education, in a way or other, lays the foundation for life-long learning (Obanya, 1999). In economically less developed countries like Nepal, it is considered of higher importance because of its impactful influence in shaping national interest and national culture. Nepal, being a noncolonized nation, had the opportunity to develop its own basic school curricula. However, perhaps, falling under neocolonial global agenda of developed countries to control economically less powerful countries through the means of 'knowledge-power', the country unfortunately lost that opportunity, and remained dependent on borrowed curricula (most often influenced from western educated elites). Perhaps, it entered (either deliberatively or under pressure) to the most subtle form of vicious circle of Neocolonialism, and school education became the most powerful indirect means for this ends. The 'politics' of 'curriculum as experts' business' and 'curriculum as monocultural text' entered in educational bureaucracy (Luitel, 2003). It welcomed the influence of foreign experts in policy-making. In the language of Luitel and Taylor (2005), the use of foreign (western) technical advisors in national policy-making, thus, introduced foreign administrative models and curricular patterns for schools. Further, Nepal's economic and political dependence to India influenced Nepali schooling practices to larger extent. Falling under Indian influence, which itself was colonized by Britain, Nepal uncritically adopted British style of education as responsible to 'enlighten' the mass. Perhaps, it is the major underlying cause behind the wider policy-practice gap observed in school education of Nepal.

Such uncritically accepted dominances were observed in many spheres of national educational plan and policies. For example, as a member of global community, Nepal made commitment to the Dakar Framework of Action (2000) for the attainment of Education for all by 2015 AD. Education for All (EFA) Goal 2 was to ensure that all children, particularly girls and children in difficult circumstances and those belonging to disadvantaged ethnic groups, have access to knowledge. It was seemingly a global humanitarian agenda. Its contribution in expanding early childhood development, ensuring access to all children, meeting the learning needs of all children (including the indigenous peoples and minorities), reducing adult illiteracy, and eliminating gender disparity (MoE, 2009) can never be ignored. However, the global call of such powerful international agencies, in a way or other, created strong pressure to the government of Nepal to introduce educational reform of western interests. Though Nepal actively engaged in making national curriculum framework, which readily addressed ongoing pursuit of equity in Nepali school education, this shift became a tool in legitimizing what Rizvi and Lingard (2010) called the 'the neoliberal social imaginary'. Unfortunately, the tacit implication therein that common curriculum standards works fine throughout the country, could not give due recognition to place-based pedagogies. It, therefore, gave space to curricular understanding as 'mono-cultural text' (Luitel, 2009), and thereby strengthened (rural/indigenous) injustice in the name of justice.

The expectation of financial incentives from multilateral aid agencies rather triggered the pressure, where Nepal required making concessions and taking certain steps favorable to the interest of those aid agencies. For example, The World Bank (among others) supported Nepal with finance, policy advice, and technical assistance (MoE, 2009) to meet such global calls. Sooner or later, in impressing those aid agencies, mere adding schools and increasing enrollment became synonymous to Nepali education. As such, as Luitel and Taylor (2005) understands it, the neocolonial influence entered and, thus, influenced educational circle of Nepal through conflicting interests of political elites and donor agencies. It might be the reasons that as observed in the action school of this study, there are many reform agendas of government (like those of local curriculum and CAS), where implementation procedures are often foreign from local contexts and school realities (Subedi, 2015). In long run, the widening policy-practice gap has adversely affected the quality (and relevance) of school education.

In spite of few praiseworthy contributions of global calls like 'education for all' and 'no child left behind' 
(for e.g., contribution in increasing school enrolment), many seemingly alike western-modern global agenda (knowingly or unknowingly) sought to limit Nepali education equivalent to training. The modernization model it advocated, which emerged in 1950s was mere an explanation of how the industrial societies of North America and Western Europe developed (Luitel \& Taylor, 2007). Based on modernization model such global agenda sought to answer, various questions of educational value aligned to western orthodoxies. For example, the questions of educational significance like- what constitutes school knowledge? Whose knowledge do schools impart? And how is that knowledge created and disseminated? - were answered in terms of western version of economy, referring to the expansion of the capitalist economy to include all places around the world into one globally integrated economic system. One visible example is the way Nepal forgot its earlier 'Gurukul ' education values, and instead, in prioritizing technical interest of curriculum, it focused more on measurable outcomes such as test scores, and continuously became less concerned to 'actual learning' of students.

Falling under neocolonial agenda of education, knowledge creation became political and ideological process. Under such circumstances, many of the Nepali politicians, academics, policy makers and administrators, because of the western education they attended, developed western-modern mindsets. Those educated elites, when they were in the responsible positions to make national educational policies, (uncritically) began to lead the government on 'their' path to modernity (Luitel \& Taylor, 2005). For many of them, modernization and globalization was synonymous to adopting western cultural practices. In long run, as recent studies shows (e.g., Muktar, 2009; Anwaruddin, 2013), such Euro-centric westernized global educational agenda eventually became counter-productive in many developing countries from Africa and Asia. This happened to Nepal as well. Recent studies on the lesson learnt from EFA implementation in various developing countries demonstrates that it was easier to achieve reforms which secure increased access to schooling; however, to secure its relevance and to enhance robust improvements in schooling quality was yet another issue that went beyond the issue of access to education (Anwaruddin, 2003). More students got access to education, but they seemingly lost their connectedness to their own life-world, and accordingly, lost the meaning of being educated. It might be the reason that educated/ uneducated youth from rural Nepal overlook the locally available resources for their living, and find excuses to leave the village.

\section{Dislocated values}

For many Nepalis, adopting western-modern worldviews involves adopting new cultural perspectives. In long run, it has suppressed local worldviews (Luitel, 2003). The perception of modernity, globalization and development as synonymous with westernization has carried with it a Eurocentric mind-set, which has continuously subjugated Nepali culture and has created a desire for westernized culture among Nepali youngsters. Therefore, the very character being portrayed by school children in Nepal (like Ranjeet in this study) clearly showed the danger of purging local values. They are demonstrating a Western character, forfeiting their own national character. The upsurge of information technology and governments' closed-eyes to make its citizen the media literate has further destroyed the originality of local Nepali cultures. Emphasis of parental communities to send their children to English medium private schools, and the emphasis of public schools to teach additional English in the name of local curriculum is rooted in neo-colonized mindsets as such.

Consequently, school leavers, in their desire to present themselves as being modernized, have ended up in fantasy, and have started to scorn the ways of their ancestors and their heritage. They have begun to go scornful towards their place and origin. Many of them feel proud in leaving their homes and families. In following such dislocated values and creeds that were shaped in their school curriculum, being emotionally and spiritually displaced, many have lost the meaning why they are educated for. In Nepal, it is a common occurrence of seeing many youth who passed through the modern school system, feel ashamed of being associated with their community. Most of them show lack of respect for their elders and parents, and for their culture.

\section{Recent Sociocultural and Political Development}

However, there are still some hopes. Nepal is undergoing political, social and educational transformation. It is in the threshold of new possibilities and prosperity. For example, the country has recently promulgated new constitution through constitutional assembly. The new constitution has paved manifold spaces to establish Nepal as independent, secular, inclusive, and democratic state (GoN, 2015). It also demands a thorough reorientation of the education system through structural and functional reforms, including the policy and regulatory frameworks. The constitution lays down the directive principles of the federal state, provinces, and local bodies on education. It is the most favorable time, where local government may use constitutional rights to develop their own contextually relevant school curriculum and implement in its service area. Further, with introduction of the federal system under this 2015 promulgated constitution, the eighth amendment of the Education Act (GoN, 2016) has strengthened the enabling environment for school education by providing the basis for structural and functional reforms.

At the same time, following the lesson learned from School Sector Reform Plan (SSRP 2009-2016), the Government of Nepal has developed School Sector Development Plan (SSDP) for the seven-year period of mid July 2016 to mid July 2023. It is in line with Nepal's vision to graduate from the status of a least developed country by the year 2022 , and to reach the status of the middle-income countries level by 2030 . The SSDP reflects the legacies of EFA and SSRP alongside new initiatives to 
address the emerging needs of the country and the people's aspiration. Following it, Nepal can make significant shift in making school education more relevant, contextualized and place-responsive. To this, following suggestion made by Luitel and Taylor (2005) is seemingly relevant-

Perhaps, the popular Nepali adage, don't forget your landscape, which is used often to remind others about their background, is appropriate to linkup with the notion of contextualization. As the adage is used to advise persons with an improved lifestyle resulting from formal education not to deviate from their cultural capital by which they are linked with their land, it also gives the sense that everything about our histories and traditions are rooted in the soil on which we live. (p.11)

\section{Conclusion}

Making anti-colonial critical look at on-going westernmodern hegemony to educational discourses and practices of Nepal, here, I am not underrating manifold inabilities of this country to shape its own educational agendas of national interest. Also, I stress that in exposing manifold needs for curriculum contextualization, it is not my intention to promote traditionalism in school education of Nepal. Instead, evidenced from lived experiences and field observation of public schools and human landscapes from rural locations of Nepal, it is my open argument that school education has to ensure its learners' sense of belonging, being, and becoming, and that while developing national curriculum framework, and policy reforms, the education policy makers of Nepal are to be aware of contextual realities of rural locations. Also, they have to be equally conscious of few 'hidden' capitalist interests of dominant powers and aid agencies.

Overall, there are manifold rationales behind the need to add 'place' and thereby initiate curriculum contextualization in schools of Nepal. As this study stressed, (1) current demographic situation i.e., village going empty (2) its current socio-economic condition with larger possibilities in agriculture and agro-based industries (3) cultural diversity with many knowledge heritages and wisdom traditions (4) inability of school graduates to take control of their locally available resources and (5) uncontrolled educational mobility of educated/ uneducated youth away from their place emphasize the need of place pedagogy in school education of Nepal.

As this study suggests, now is the time to look for local knowledge with global relevance. Therefore, there is need to avoid the universalistic impulse in school pedagogies of Nepal. Being mindful at the discomforts initiated by decontextualized school curriculum in the past, it is the right time for Nepal to cultivate its national culture through relevant education practices. If current sociopolitical changes as discussed above are not addressed by effective exercises on education, perhaps, falling under neo-liberal political agenda of secularism, and hegemonic globalization, the country is likely to fall further, lowering the national pride of school graduates in higher degree than it is experienced these days. The slogan, "village going empty', is likely to continue. As such, starting from working on contextualized school education, rediscovering its lost and suppressed intellectual heritage may work productive.

However, only figuring the neocolonial agenda of education, and its aftereffects in Nepal, may not work productive. It demands thoughtful actions, backed by alternative (perhaps indigenous) notions of evidences and research process. It has to move beyond legitimizing technically guided capitalist interests accountable for 'measurable educational outcomes'. For this, as this study stress, bracketing itself from the influence, and/or hidden interests of power groups and multi-national aid agencies, Nepal has to come with contextually relevant place pedagogy of its own. It has to initiate learning for living in the place, not leaving it.

\section{Acknowledgement:}

We would like to thank the study school and the stakeholders who have provided time for us to actively participate in this study. We prepared this paper with the support from NORHED/Rupantaran project entitled 'Innovations in Teaching and Learning through Contextualized Approaches to Increase the Quality, Relevance and Sustainability of Education in Nepal'. The project has been jointly implemented in Nepal by Tribhuvan University (TU), Kathmandu University (KU) and Norwegian University of Life Sciences (NMBU). Authors are grateful to the project coordinators for their valuable supports.

\section{Funding:}

The author(s) disclosed receipt of the following financial support for the research, authorship, and/or publication of this article: This project was funded by NORHED Rupantaran project in Nepal.

\section{Ethical approval for the research:}

From KUSOED's research committee's ethical approval of the first author's $\mathrm{PhD}$ research proposal

\section{Conflict of Interest:}

The author(s) declared no potential conflicts of interest with respect to the research, authorship, and/or publication of this article.

Ethical Conduct of Research:

We declare that this research has been conducted ethically

\section{Authors' note:}

This study is a part of the first author's doctoral dissertation.

\section{References}

Anwaruddin, S. M. (2013). Neoliberal universities and the education of arts, humanities and social sciences in Bangladesh. Policy Futures in Education, 11(4), 364374.

Awasthi, L. D. (2004). Exploring monolingual school practices in multilingual Nepal (Unpublished doctoral dissertation). The Danish University of Education, Copenhagen, Denmark.

CDC (2005). National curriculum framework for school education in Nepal. Ministry of Education and Sports, Curriculum Development Centre.

CDC (2010). The local curriculum: Resource and training 
manual (In Nepali). Ministry of Education and Sports, Curriculum Development Centre

Corbett, M. (2007). Learning to leave: The irony of schooling in a coastal community. Black Point NS: Fernwood Publishing.

GoN (2015). The Constitution of Nepal (September 2015). Kathmandu: Government of Nepal. Available at: http:// www.mofa.gov.np/the-constitution-of-nepal

GoN (2016). Eighth Amendment to the Education Act (1971). June 2016. Kathmandu: Government of Nepal.

Luitel, B. C. (2003). Narrative explorations of Nepali mathematics curriculum landscapes: An epic journey. Unpublished Master's Project, Curtin University of Technology, Perth.

Luitel, B. C., \& Taylor, P. C. (2005, Apr). Overcoming culturally dislocated curricula in a transitional society: An autoethnographic journey towards pragmatic wisdom. Paper presented at the annual meeting of the American Educational Research Association (AERA).

Luitel, B. C., \& Taylor, P. C. (2007). The shanai, the pseudosphere and other imaginings: Envisioning culturally contextualized mathematics education Cultural Studies of Science Education 2(3), 621-638.

Luitel, B. C. (2009). Culture, worldview and transformative philosophy of mathematics education in Nepal: A cultural-philosophical inquiry. Unpublished Thesis, Curtin University, Perth.

McKenzie, M. \& Tuck, E. (2015). Place in research: theory, methodology, and methods. Routledge

MoE (2009). School Sector Reform Programme: 2009 2015. Ministry of Education, Government of Nepal. Available at: http://www.moe.gov.np/article/166/ school-sectorreform-plan-ssrp.html.

MoE (2016). School sector development plan, Nepal, 2016/17 2022/23. Ministry of Education, Government of Nepal.

Mukhtar, A. (2009). The neoliberalization of education services (not including higher education): Impact on workers' socioeconomic security, access to services, democratic accountability, and equity - A case study of Pakistan. In D. Hill \& E. Rosskam (Eds.), The developing world and state education: Neoliberal depredation and egalitarian alternatives (pp. 125139). Routledge.

Obanya, M. (1999). The dilemma of education in Africa. UNESCO.

Rancière, J. (2007). The emancipated spectator. Art forum International, 45(7), 270-280.

Rizvi, F. \& Lingard, B. (2010). Globalizing Education Policy. Routledge.

Subedi, K. R. (2015). Perceptions of primary school teachers' towards the local curriculum (In Nepali), Pragya Manch, 28(13), 18-24.

Taylor, P. (2007). Making learning relevant: Principles and evidence from recent experiences: Synthesis of an institutional, regional, and international review. World Bank.

Wagle, S. K. (2016). From hopelessness to hope at academics: A self-reflective inquiry on conditioning of learning emotions. Unpublished dissertation, Kathmandu University.

Shree Krishna Wagle is a $\mathrm{PhD}$ research fellow at Kathmandu University, School of Education, Nepal. MPhil graduate in educational leadership, Shree particularly makes research studies in the field related to educational philosophy, learning psychology, and ecological spirituality in education. At present, evidenced from a case of participatory action research project from public school of rural Nepal, together with Parbati Dhungana and colleagues at KUSOED, Shree is exploring possibilities for participatory approaches to contextualized teaching and learning.

Email: seerishakrill@yahoo.com

Bal Chandra Luitel, PhD, (2009) is a Professor of Mathematics Education at Kathmandu University. He leads transformative educational research group at Kathmandu University, School of Education. Subscribing to multiple epistemic metaphors, Bal's research aims at developing a transformative philosophy of education in Nepal. He has published articles including Luitel, B.C. (2018), a mindful inquiry towards transformative curriculum vision for inclusive mathematics education.

Email: bcluitel@kusoed.edu.np

Erling Krogh, $\mathrm{PhD}$, is a Professor at Section for Learning and Teacher Education at Norwegian University of Life Sciences. In Norway, he has coordinated national projects on cooperation between primary schools and farmers, using the farm as a learning arena, and on development of school gardens. Since 2011, together with Sigrid Gjøtterud and colleagues from Sokoine University of Agriculture in Tanzania, he has focused on and published from participatory action research in Tanzania. Currently, he is cooperating with colleagues at Kathmandu University on similar projects.

Email: Erling.krogh@nmbu.no 